\section{(6) OPEN ACCESS}

\title{
Timing of the decline in physical activity in childhood and adolescence: Gateshead Millennium Cohort Study
}

\author{
Mohammed Abdulaziz Farooq, ${ }^{1,2}$ Kathryn N Parkinson, ${ }^{3}$ Ashley J Adamson, ${ }^{3,4}$ \\ Mark S Pearce, ${ }^{3}$ Jessica K Reilly, ${ }^{4}$ Adrienne R Hughes, ${ }^{1}$ Xanne Janssen, ${ }^{1}$ \\ Laura Basterfield, ${ }^{4}$ John J Reilly ${ }^{1}$
}

\begin{abstract}
- Additional material is published online only. To view please visit the journal online (http://dx.doi.org/10.1136/ bjsports-2016-096933)
\end{abstract}

${ }^{1}$ Physical Activity for Health Group, School of Psychological Sciences \& Health, University of Strathclyde, Glasgow, UK ${ }^{2}$ Aspetar Orthopaedic and Sports Medicine Hospital, Doha, Qatar

Institute of Health \& Society, Newcastle University, Newcastle upon Tyne, UK

${ }^{4}$ Human Nutrition Research Centre, Newcastle University, Newcastle upon Tyne, UK

Correspondence to Professor John J Reilly; john.j.reilly@strath.ac.uk

Accepted 22 December 2016 Published Online First 13 March 2017
Check for updates

To cite: Faroog MA, Parkinson KN, Adamson AJ, et al. Br I Sports Med 2018:52:1002-1006.

\begin{abstract}
Background and aim There is a widely held and influential view that physical activity begins to decline at adolescence. This study aimed to identify the timing of changes in physical activity during childhood and adolescence.

Methods Longitudinal cohort study (Gateshead Millennium Study) with 8 years of follow-up, from North-East England. Cohort members comprise a socioeconomically representative sample studied at ages 7, 9, 12 and 15 years; 545 individuals provided physical activity data at two or more time points. Habitual total volume of physical activity and moderate-to-vigorous intensity physical activity (MVPA) were quantified objectively using the Actigraph accelerometer over 5-7 days at the four time points. Linear mixed models identified the timing of changes in physical activity across the 8-year period, and trajectory analysis was used to identify subgroups with distinct patterns of age-related changes.
\end{abstract}

Results Four trajectories of change in total volume of physical activity were identified representing $100 \%$ of all participants: all trajectories declined from age 7 years. There was no evidence that physical activity decline began at adolescence, or that adolescent declines in physical activity were substantially greater than the declines during childhood, or greater in girls than boys. One group (19\% of boys) had relatively high MVPA which remained stable between ages 7 and 15 years. Conclusions Future policy and research efforts to promote physical activity should begin well before adolescence, and should include both boys and girls.

\section{INTRODUCTION}

Systematic reviews have established that daily physical activity, particularly moderate-to-vigorous intensity physical activity (MVPA), is important for both the current and future health of children and adolescents. ${ }^{12}$ For many years the prevailing view among researchers, policy makers, and health and education practitioners, based largely on subjective measurement of physical activity, has been that levels of physical activity are adequate during childhood, but decline dramatically during adolescence, with the adolescent decline being much more marked in girls than boys. ${ }^{3-6}$ A more marked decline in girls may be related to their advanced pubertal maturation compared with boys, though the relative importance of biological and environmental influences on child and adolescent physical activity remains unclear. ${ }^{7}$ Much research and policy effort has been directed at adolescent girls, considered to be the 'high risk group' for low physical activity, ${ }^{3-6}$ with the implicit or explicit assumption that children and boys are at low risk. Many national and international physical activity surveillance programmes focus on adolescents, ${ }^{8}$ also based on implicit or explicit assumptions that adolescence is the stage of the life course when physical activity declines dramatically.

While levels of MVPA among adolescents are typically much lower than recommended ${ }^{8}$ there is actually very little evidence that MVPA declines with the onset of adolescence, or that adolescent declines in MVPA are more marked in girls than boys. Dumith et $a l^{9}$ published the most recent systematic review of changes in physical activity during adolescence, with 26 eligible longitudinal studies. Of these eligible studies only $2 / 26$ included objective measures of the intensity of physical activity (accelerometry), most (16/26) were from the USA, and the representativeness of the samples in the eligible studies was usually unclear. $^{9}$ Moreover, since most studies completed data collection before 2000 , they probably lack generalisability to contemporary populations given recent and dramatic societal changes: declines in active commuting, ${ }^{10}$ in the technology being used by children ${ }^{10}$ (eg, the ubiquitous nature of new screen-based media), ${ }^{11}$ and in overweight and obesity (which appear to reduce physical activity). ${ }^{12}$ The International Children's Accelerometry Database, though cross-sectional, suggests that objectively measured physical activity may be in decline in both sexes from around the age of school entry. ${ }^{13}$ We are aware of only one single longitudinal study which measured physical activity across childhood and adolescence: in children born in Iowa in the early 1990s physical activity declined, in both sexes, from age 5 years in most study participants. ${ }^{14}$ In summary, despite the well-established and influential concept that declines in physical activity begin at adolescence, an emerging body of evidence suggests that declines may occur earlier, but there is currently very little high-quality longitudinal evidence on the timing of changes in physical activity across childhood and adolescence in contemporary cohorts. The primary aim of the present study was 
therefore to describe the timing of changes in physical activity across childhood and adolescence, to identify when changes take place.

\section{METHODS}

\section{Participants, recruitment, consent and study design}

Participants were from the Gateshead Millennium Cohort Study (GMS). Details of this cohort study have been published previously, ${ }^{15}$ but, in brief, the sample was socioeconomically representative of the north-east of England. ${ }^{15}$ This was a longitudinal study and the intention was to repeat measures in as many of the original cohort members as possible at subsequent time points. Habitual physical activity measurements in the cohort began when participants were 7 years of age (October 2006 to December 2007), and were repeated at 9 years of age (October 2008 to September 2009), 12 years of age (October 2011 to December 2012) and 15 years of age (September 2014 to September 2015). The study was approved by the Gateshead and South Tyneside Local National Health Service Research Ethics Committee for data collection at age 7 years, and by the Newcastle University Faculty of Medical Sciences Ethics Committee for subsequent measures. Informed written consent was obtained from the parent/main guardian of each child, and children and adolescents assented to participation.

\section{Objective measurement of total volume of physical activity and MVPA}

Habitual total 'volume' of physical activity (ie, light intensity physical activity combined with MVPA) and MVPA were measured using Actigraph GT1M (Actigraph, Pensacola, FL, USA) accelerometers at all four time points. The Actigraph is a small, unobtrusive and lightweight monitor with high validity (relative to reference measures of physical activity, direct observation and energy expenditure), high reliability and low reactivity in children, ${ }^{16}$ and has been used successfully in many paediatric physical activity studies internationally. ${ }^{13}$

The methodology for measurement of physical activity in the GMS cohort is described in detail elsewhere. ${ }^{17-21}$ In brief, participants were asked to wear the accelerometer during waking hours for 7 days, removing only for bed and water-based activities such as showering, bathing and swimming. Families were also given a $\log$ sheet to note when the monitor had been worn and removed each day. The accelerometers were set to record data in $15 \mathrm{~s}$ sampling intervals (epochs) throughout the period the accelerometer was worn. Data were reduced manually using accelerometry output and log sheets, as described previously, ${ }^{17-21}$ to delete periods of non-wear time (corresponding to times noted by the parent, child or adolescent, as unworn). Total volume of physical activity was measured using the accelerometer output or counts per minute (cpm). Measuring the intensity of physical activity, specifically MVPA, requires that an accelerometer output threshold-'cut-off point'-is applied. Two evidence-based but distinct 'cut-off points' have been used widely in the literature, but in the present study the cut-point of 574 counts per $15 \mathrm{~s}$ was used $^{22}$ and it has acceptable classification accuracy. ${ }^{23}$ Since the Actigraph cut-off points used in this study were derived from studies using Actigraph model 7164 and the more recent Actigraph GT1M model has a consistent bias of $9 \%$ relative to model $7164,{ }^{24} \mathrm{a}+9 \%$ correction was applied to the raw accelerometry data before applying cut-off points. In UK children there are small seasonal variations in objectively measured habitual physical activity ${ }^{19} 2025$ and so accelerometry measurements at ages 7,9 and 12 years were made at the same time of the year as described previously ${ }^{17-21}$; at age 15 years close matching for season was not possible in all cases, hence accelerometry data were adjusted for season (summer or winter) during analysis.

\section{Anthropometric and descriptive characteristics of study participants}

Height was measured to $0.1 \mathrm{~cm}$ with a Leicester portable height measure (Chasmors, London, UK) and weight measured to $0.1 \mathrm{~kg}$ in light indoor clothing and \% body fat estimated with a Tanita TBF300MA (Chasmors, London UK). ${ }^{17-21}$ Body mass index $\left(\mathrm{BMI}, \mathrm{kg} / \mathrm{m}^{2}\right.$ ) was calculated, and $\mathrm{z}$-scores estimated to UK 1990 population reference data. ${ }^{26}$ Socioeconomic status was assessed using Townsend scores at birth, ${ }^{27}$ an area-based measure derived from the UK census.

\section{Statistical analysis}

The sample size for the present study was fixed by the size of the recruited cohort at age 7 years, and the extent of sample attrition over the 8-year period. However, the sample size was similar to or larger than most previous studies with two measures of physical activity. ${ }^{914}$ Further, the accuracy of both the reported levels of physical activity and sedentary behaviour and the changes in levels over the 2-year period is increased by the use of accelerometry and the longitudinal design and analyses used by the study. Linear mixed models were used with SPSS V.21.0 statistical software to describe age-related changes in physical activity. Gender, age groups and their interaction were fixed factors and participant ID was the clustering random variable using unstructured covariance structure for age group as repeated measurement. For the MVPA data at age 15 years, season (winter or summer) was added as a factor to adjust for seasonal variation in physical activity. Post hoc pairwise differences were reported as absolute change with 95\% CIs after Bonferroni adjustment.

Group-based modelling of longitudinal data to identify distinct trajectories of age-related changes in physical activity was performed using the Traj module plug-in in STATA V.11.0. This method, initially developed by Nagin et $a l,{ }^{28}$ has recently been applied to longitudinal physical activity data. ${ }^{14}$ Groupbased modelling to identify trajectories can identify patterns of change, incorporating multiple different time trends and multiple different levels at baseline. ${ }^{28}$ Given potential differences in trajectories of physical activity change between the sexes, they were modelled separately for boys and girls. The trajectories were modelled using either quadratic or linear trends. In a step-by-step manner, we increased the number of distinct trajectories that can be extracted from the data, first by evaluating the posterior probabilities for each model for tenability and by comparing fit statistics as defined by the Bayesian Information Criterion (BIC) to be lowest. The process of specifying the number of distinct trajectories and selection of linear versus quadratic trend for each trajectory continued until there was no substantial improvement in model fit. Non-significant quadratic terms were replaced with linear terms irrespective of significance to ensure parsimony of the model. ${ }^{29}$ Using a maximum probability assignment rule, each participant was classified under a trajectory for which posterior membership probability was the highest. Trajectories and the 95\% CIs surrounding each trajectory were plotted.

\section{RESULTS}

\section{Characteristics of study participants}

A total of 545 individuals provided accelerometry data twice, and 217 at all four time points, with the sample size at each 
Table 1 Physical activity measurements and characteristics (Mean (SD) of study participants included in the analysis at the four time points)

\begin{tabular}{|c|c|c|c|c|c|c|c|c|}
\hline & \multicolumn{4}{|l|}{ Boys } & \multicolumn{4}{|l|}{ Girls } \\
\hline & $\begin{array}{l}\text { Age } 7 \\
(n=217)\end{array}$ & $\begin{array}{l}\text { Age } 9 \\
(n=209)\end{array}$ & $\begin{array}{l}\text { Age 12 } \\
(n=176)\end{array}$ & $\begin{array}{l}\text { Age 15 } \\
(n=131)\end{array}$ & $\begin{array}{l}\text { Age } 7 \\
(n=214)\end{array}$ & $\begin{array}{l}\text { Age } 9 \\
(n=219)\end{array}$ & $\begin{array}{l}\text { Age 12 } \\
(n=209)\end{array}$ & $\begin{array}{l}\text { Age 15 } \\
(n=147)\end{array}$ \\
\hline Age (years) & $7.5(0.5)$ & $9.3(0.4)$ & $12.5(0.3)$ & $15.2(0.4)$ & $7.5(0.4)$ & $9.3(0.4)$ & $12.5(0.3)$ & $15.2(0.4)$ \\
\hline \multicolumn{9}{|l|}{ Anthropometry } \\
\hline Height $(\mathrm{cm})$ & $125.5(5.7)$ & $135.9(6.3)$ & $154.2(8.7)$ & $171.6(8.1)$ & $124.7(5.8)$ & $135.4(6.3)$ & $155.2(7.3)$ & $163.0(6.2)$ \\
\hline Weight (kg) & $26.5(5.5)$ & $33.0(7.2)$ & $48.3(11.8$ & $63.4(14.5)$ & $26.7(5.9)$ & $33.8(7.7)$ & $51.0(12.4)$ & $61.8(14.4)$ \\
\hline BMI $\left(\mathrm{kg} / \mathrm{m}^{2}\right)$ & $16.7(2.4)$ & $17.7(2.8)$ & $20.1(3.7)$ & $21.4(4.0)$ & $17.1(2.6)$ & $18.3(3.0)$ & $21.0(4.0)$ & $23.2(4.6)$ \\
\hline BMI z-score & $0.4(1.2)$ & $0.5(1.2)^{\dagger}$ & $0.7(1.2)^{\dagger \ddagger}$ & $0.5(1.3)^{\S}$ & $0.4(1.1)$ & $0.6(1.1)^{\dagger}$ & $0.7(1.1)^{\dagger \ddagger}$ & $0.8(1.1)^{\dagger \neq}$ \\
\hline Fat mass $(\mathrm{kg})$ & $6.5(3.2)$ & $8.7(5.0)$ & $12.0(8.4)$ & $14.2(10.6)$ & $6.3(3.6)$ & $9.2(5.0)$ & $14.2(8.6$ & $21.8(11.5)$ \\
\hline \multicolumn{9}{|l|}{ Accelerometer data } \\
\hline Wear time (min/day) & $672(74.5)$ & $673(77.6)$ & $712(87.6$ & $725(88.4)$ & $667(70.9)$ & $671(75.6)$ & $718(82.8)$ & $720(87.2)$ \\
\hline Days worn & $6.4(1.0)$ & $5.9(1.3)$ & $5.8(1.4$ & $5.3(1.6)$ & $6.2(1.2)$ & $5.9(1.3)$ & $5.7(1.5)$ & $5.4(1.7)$ \\
\hline Total physical activity (cpm) $)^{\Uparrow}$ & $780(223)^{\ddagger \S^{*}}$ & $715(192))^{\S^{*}}$ & $558(189)^{*}$ & $482(154)$ & $746(222) \ddagger^{\S}$ & $653(193)^{\S^{*}}$ & $469(191)^{\S^{*}}$ & 400 (156) \\
\hline $\operatorname{MVPA}(\min / \text { day })^{\pi}$ & $75.5(25.5)^{\ddagger \S^{*}}$ & $70.0(23.9)^{\S^{*}}$ & $60.3(24.4)^{*}$ & $51.4(22.4)$ & $63.4\left(20.9^{\ddagger \S^{*}}\right.$ & $56.4(19.8)^{\S^{*}}$ & $47.4(20.9)^{*}$ & $41.0(16.8)$ \\
\hline
\end{tabular}

$\mathrm{BMI}$, body mass index; cpm, accelerometer counts per min, a measure of the total amount of physical activity (light intensity physical activity and MVPA combined); MVPA, moderate-to-vigorous intensity physical activity, adjusted for season (winter vs summer) at age 15 years

$\dagger$, significantly higher than age 7 years; $¥$, significantly higher than age 9 years; $§$, significantly higher than age 12 years; $\uparrow$, Estimated marginal means derived from linear mixed model analysis; ${ }^{*}$, significantly higher than age 15 years.

time point as follows: 431 (7 years), 428 (9 years), 385 (12 years) and 278 (15 years). The study flow diagram is provided in online supplementary figure 1. Participants who provided data at least twice had similar physical activity and similar BMI-z scores at baseline compared with those who had missing or invalid accelerometer data. Girls with more than two missing/ invalid data points had slightly higher BMI z-scores at baseline than those with complete data, but similar physical activity.

\section{Summary data on physical activity at each of the four measurements}

Summary data on total volume of physical activity (accelerometer cpm, a measure of light intensity physical activity and MVPA combined) and MVPA, at each time point between ages 7 and 15 years, are shown in table 1 . Mean accelerometry monitoring period ranged from 5.3 to 6.4 days and 667 to $725 \mathrm{~min}$ per day across the four time points.

\section{Changes in physical activity analysed longitudinally using trajectory analysis}

The longitudinal trajectory analyses for changes in total volume of physical activity are shown in figure 1 for boys and girls: in the boys three distinct trajectories were identified, but in all three subgroups, representing $100 \%$ of the sample, the total volume of physical activity declined across the 8-year period from age 7 years; in the girls a single trajectory of declining total physical activity across the 8-year period from age 7 years characterised all study participants. None of the trajectories of total volume of physical activity showed initial high levels followed by sharp adolescent declines.

The longitudinal trajectories of change in MVPA for boys and girls are shown in figure 2. In boys, four distinct subgroups were identified: low and relatively stable/slowly declining MVPA from age 7 years across the 8 years ( $3 \%$ of the sample); initially high at age 7 years, but rapidly declining from age 7 years $(17 \%$ of the sample); gradually declining from age 7 years (61\% of the sample); relatively high and stable or increasing from age 7 years (19\% of the sample).

The longitudinal trajectories of change in MVPA of girls are also shown in figure 2. Three distinct trajectories were identified: low and relatively stable/ with modest declines (19\%); gradually declining from age 7 years (62\%); high initial MVPA with steeper declines from age 7 years (19\%). None of the trajectories of MVPA in either boys or girls were characterised by high and stable childhood values followed by sharp adolescent declines.
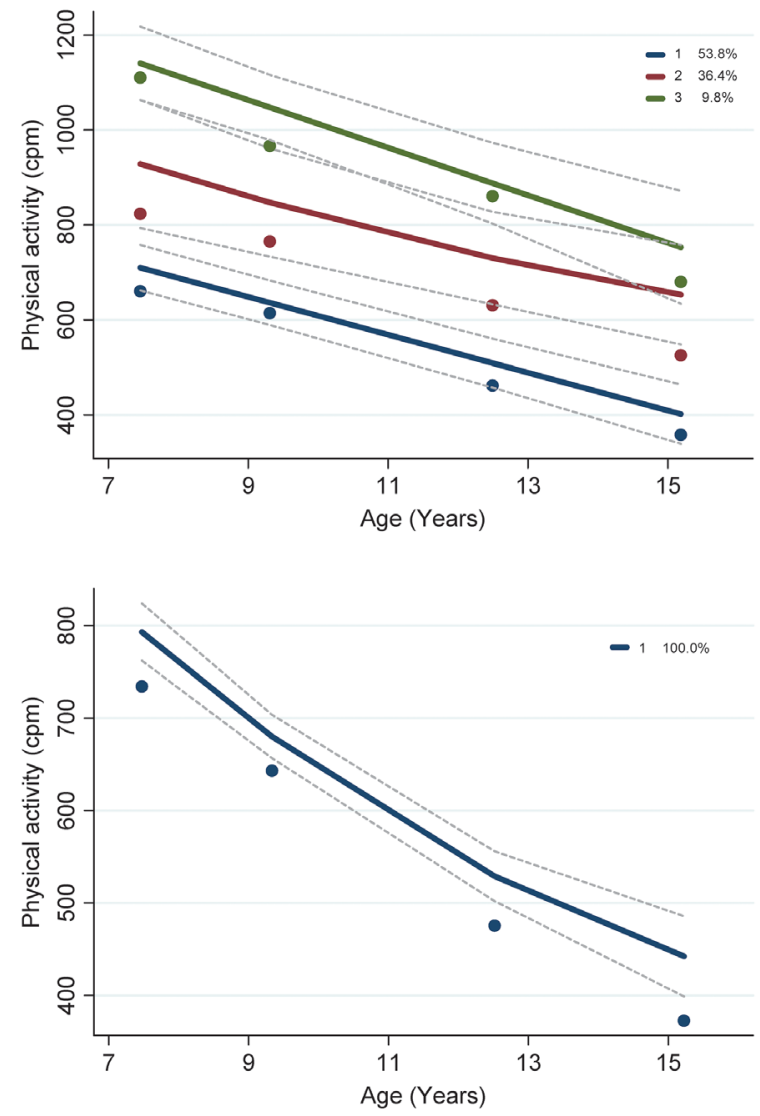

Girls

Figure 1 Change in total physical activity in boys (1A) and girls (1B) based on trajectory analysis. 


\section{DISCUSSION}

\section{Main study findings and implications}

The present study suggests that total volume of physical activity is already declining by age 7 years in the UK. The present study found that $100 \%$ of boys and girls fitted into longitudinal trajectories which were inconsistent with the orthodox view that physical activity begins to decline at adolescence, declines much more rapidly at adolescence and/or declines much more rapidly in adolescent girls than boys. The present study therefore suggests that much of the current UK and international policy and practice in this area, based on the orthodox view, is not evidencebased. The main implication of our findings for future research and public health policy in physical activity and health is the need for a much greater emphasis on childhood rather than adolescence, and on both boys and girls.

Trajectories of change in MVPA were more complex than trajectories of change in total volume of physical activity, but it is of note that in around 19\% of boys MVPA was relatively high and fairly stable across the 8 -year period. These distinct trajectories of physical activity are new, and their determinants are unclear, but understanding why a minority of participants maintained a relatively high and stable level of MVPA across childhood and adolescence would help inform future policy and clinical practice.

\section{Consistency of evidence from the present study with other studies}

The International Children's Accelerometry Database (ICAD), a global data-pooling initiative, has recently demonstrated that mean values for total volume of physical activity and MVPA both appear to decline steadily after the age of 5 years. ${ }^{13}$ While this ICAD study was cross-sectional, and most samples not contemporary, ICAD data also provide no support for the view that physical activity decline either begins at adolescence, or increases markedly at adolescence. In the UK, recent nationally representative but cross-sectional accelerometry measures also suggest that total volume of physical activity begins to decline around the age of school entry. ${ }^{30}$

Since the recent systematic review on changes in physical activity during adolescence by Dumith et al, ${ }^{9}$ four English cohort studies have reported on objectively measured longitudinal changes in MVPA during adolescence, though these studies do not span both childhood and adolescence. Harding et $\mathrm{al}^{31}$ (n 363; age 12-15 years) and Mitchell et al ${ }^{32}$ (n 5436; 12-16 years) found negligible declines in objectively measured MVPA during adolescence. Corder et $a l^{6}$ (n 480; 10-14 years) and Collings et $a l^{33}$ (n 144; 15-17 years) found small declines in MVPA which were slightly greater in boys than girls. In summary, recent English longitudinal studies which used objective measures of physical activity are consistent with the present study in suggesting that physical activity does not decline especially markedly at adolescence, and does not decline more markedly in girls than boys during adolescence.

Data from the Iowa Bone Development Study were consistent with the present study in suggesting that total volume of physical activity declined either steadily or dramatically from age 5 years in $>70 \%$ of participants. ${ }^{14}$ Other evidence is also consistent with the findings of the present study in suggesting that lifestyles of English children become particularly 'obesogenic' during mid-childhood. In the Avon Longitudinal Study of Parents and Children cohort in England for example the incidence (appearance of new cases) of obesity across childhood and adolescence peaked around age 7 years, ${ }^{34}$

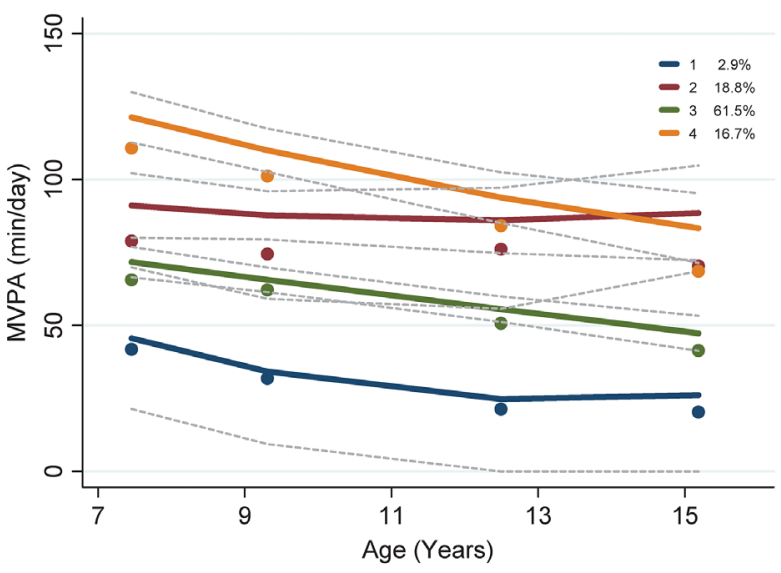

Figure 2 Change in moderate-to-vigorous intensity physical activity in boys $(2 \mathrm{~A})$ and girls $(2 \mathrm{~B})$ based on trajectory analysis.

and among non-obese individuals the rate of excessive weight gain also peaked at the same time. ${ }^{35}$ The recent systematic review by Tanaka et al also found that accelerometer-measured daily sedentary time increased from around the age of school entry, and as sedentary time increased with age physical activity was displaced. ${ }^{36}$

\section{Study strengths and weaknesses}

The main strengths of the present study were the longitudinal design, the high quality objective measures of physical activity, the socioeconomically representative sample and the contemporary nature of the cohort. One weakness may be generalisability to populations with substantially different physical, social and/ or policy environments. Further research will therefore be necessary to determine whether or not the findings of the present study are generalisable to other populations. The present study aimed to describe when changes in physical activity occurred. The issue of why any changes take place (eg, the relative importance of biological versus environmental factors) ${ }^{7}$ is important, but is a distinct question which was beyond the scope of the present study. Changes in physical activity arise as a result of a complex and currently poorly understood ${ }^{7}$ combination of biological and environmental influences. An improved understanding of why changes in physical activity take place and why individuals follow one trajectory rather than another, would also be important to future public health applications, but would require measures which were not available in the present study (eg, ideally direct measures of biological variables such as pubertal maturation). ${ }^{7}$ Trajectory analysis can also act as a 
tool to predict future MVPA based on current MVPA status, and future research could also identify how accurate such predictions might be. The trajectory analyses identified relatively large subgroups, with one exception: the 3\% of boys with low and relatively stable/slowly declining MVPA over the 8 years. Exclusion of this subgroup would have reduced model fit as judged by the BIC and CIs around the groups, and so it was retained. Future studies would be useful to confirm whether or not this small group exists in other populations. Finally, the periods between the four measurement periods in the present study were chosen so as to be adequate to detect longitudinal changes in physical activity between measurements (ie, to permit real changes to be distinguishable from measurement imprecision). However, timing of measurements was determined largely by the availability of grant funding, and more frequent measurements might have provided more nuanced evidence on the timing of changes.

\section{CONCLUSIONS}

The present study suggests that physical activity is in decline in most individuals of both sexes by age 6-7 years in the UK. The study questions the concept of the adolescent girl as a priority for research and policy effort in physical activity. Future research and public health policy should focus on (A) preventing the decline in physical activity which begins in childhood, not adolescence and (B) providing an improved understanding of the determinants of the different physical activity trajectories, including an understanding of the relative importance of biological and environmental influences.

\section{What are the findings?}

- Physical activity declines markedly during childhood, and the age-related decline does not begin at adolescence

- The physical activity decline from childhood occurs in both boys and girls

- Physical activity decline is not uniform - a small but significant minority of boys maintained relatively high and stable levels of moderate-to-vigorous intensity physical activity across childhood and adolescence

\section{How might it impact on clinical practice in the future?}

- Future efforts to arrest age-related decline in physical activity should begin well before adolescence

- We should abandon the concept of 'high risk groups' (eg, adolescent girls) for low physical activity—most of the paediatric population is at high risk

Acknowledgements The authors thank PCT, Gateshead Education Authority, local schools, the External Reference Group, the research team for support in conducting the study, and especially thank the families and children/adolescents for participating in the study.

Open access This is an open access article distributed in accordance with the Creative Commons Attribution Non Commercial (CC BY-NC 4.0) license, which permits others to distribute, remix, adapt, build upon this work non-commercially, and license their derivative works on different terms, provided the original work is properly cited and the use is non-commercial. See: http://creativecommons.org/ licenses/by-nc/4.0/

(c) Article author(s) (or their employer(s) unless otherwise stated in the text of the article) 2018. All rights reserved. No commercial use is permitted unless otherwise expressly granted.

\section{REFERENCES}

1 Janssen I, Leblanc AG. Systematic review of the health benefits of physical activity and fitness in school-aged children and youth. Int J Behav Nutr Phys Act 2010;7:40.

2 Timmons BW, Leblanc AG, Carson V, et al. Systematic review of physical activity and health in the early years (aged 0-4 years). App/ Physiol Nutr Metab 2012;37:773-92.

3 Physical Activity Review Group. Five year review of 'Let's make Scotland more active: a strategy for physical activity': Update statement from the review group. Edinburgh: NHS Health Scotland, 2010.

4 Sportscotland. Increasing demand for sport and physical activity for adolescent girls in Scotland: Exploring issues and suggesting solutions. Edinburgh: sportscotland, 2006.

5 Activity P, Alliance $\mathrm{H}$. Physical activity and adolescent girls - Knowledge Exchange Network. 2009. http://www.paha.org.uk/Feature/physical-activity-and-adolescentgirls-knowledge-exchange-network (accessed Jul 2016).

6 Corder K, Sharp SJ, Atkin AJ, et al. Change in objectively measured physical activity during the transition to adolescence. Br J Sports Med 2015;49:730-6.

7 Sherar LB, Cumming SP, Eisenmann JC, et al. Adolescent biological maturity and physical activity: biology meets behavior. Pediatr Exerc Sci 2010;22:332-49.

8 Hallal PC, Andersen LB, Bull FC, et al. Lancet Physical Activity Series Working Group. Global physical activity levels: surveillance progress, pitfalls, and prospects. Lancet 2012:380:247-57.

9 Dumith SC, Gigante DP, Domingues MR, et al. Physical activity change during adolescence: a systematic review and a pooled analysis. Int J Epidemiol 2011;40:685-98.

10 Pratt M, Sarmiento OL, Montes F, et al. Lancet Physical Activity Series Working Group. The implications of megatrends in information and communication technology and transportation for changes in global physical activity. Lancet 2012;380:282-93.

11 Christakis DA. Interactive media use at younger than the age of 2 years: time to rethink the American Academy of Pediatrics guideline? JAMA Pediatr 2014;168:399-400.

12 Bauman AE, Reis RS, Sallis JF, et al. Lancet Physical Activity Series Working Group. Correlates of physical activity: why are some people physically active and others not? Lancet 2012;380:258-71.

13 Cooper AR, Goodman A, Page AS, et al. Objectively measured physical activity and sedentary time in youth: the International children's accelerometry database (ICAD) Int J Behav Nutr Phys Act 2015:12:113.

14 Kwon S, Janz KF, Letuchy EM, et al. Developmental trajectories of physical activity, sports, and television viewing during childhood to young adulthood: lowa bone development study. JAMA Pediatr 2015;169:666-72.

15 Parkinson KN, Pearce MS, Dale A, et al. Cohort profile: the Gateshead Millennium Study. Int J Epidemio/ 2011;40:308-17.

16 Reilly JJ, Penpraze V, Hislop J, et al. Objective measurement of physical activity and sedentary behaviour: review with new data. Arch Dis Child 2008;93:614-9.

17 Basterfield L, Adamson AJ, Frary JK, et al. Gateshead Millennium Study Core Team. Longitudinal study of physical activity and sedentary behavior in children. Pediatrics 2011;127:e24-e30

18 Basterfield L, Pearce MS, Adamson AJ, et al. Gateshead Millennium Study Core Team. Physical activity, sedentary behavior, and adiposity in English children. Am J Prev Med 2012:42:445-51.

19 King AC, Parkinson KN, Adamson AJ, et al. Gateshead Millennium Study Core Team. Correlates of objectively measured physical activity and sedentary behaviour in English children. Eur J Public Health 2011;21:424-31.

20 Pearce MS, Basterfield L, Mann KD, et al. Gateshead Millennium Study Core Team. Early predictors of objectively measured physical activity and sedentary behaviour in 8-10 year old children: the Gateshead Millennium Study. PLoS One 2012;7:e37975.

21 Basterfield L, Adamson AJ, Pearce MS, et al. Stability of habitual physical activity and sedentary behavior monitoring by accelerometry in 6- to 8-year-olds. J Phys Act Health 2011;8:543-7.

22 Evenson KR, Catellier DJ, Gill K, et al. Calibration of two objective measures of physical activity for children. J Sports Sci 2008;26:1557-65.

23 Trost SG, Loprinzi PD, Moore R, et al. Comparison of accelerometer cut points for predicting activity intensity in youth. Med Sci Sports Exerc 2011:43:1360-8.

24 Corder K, Brage S, Ramachandran A, et al. Comparison of two Actigraph models for assessing free-living physical activity in Indian adolescents. J Sports Sci 2007;25:1607-11.

25 Carson V, Spence JC. Seasonal variation in physical activity among children and adolescents: a review. Pediatr Exerc Sci 2010;22:81-92.

26 Cole TJ, Freeman JV, Preece MA. Body mass index reference curves for the UK, 1990 Arch Dis Child 1995;73:25-9.

27 Townsend P, Phillimore P. Beattie A. Health and Deprivation: Inequality in the North. London: Croom Helm, Limited, 1988.

28 Nagin D. Group-Based Modeling of Development. Cambridge: Harvard University Press, 2005.

29 Helgeson VS, Snyder P, Seltman H. Psychological and physical adjustment to breast cancer over 4 years: identifying distinct trajectories of change. Health Psychol 2004:23:3-15

30 Scotland FS. National diet and nutrition survey rolling programme results from years 1-4 (combined) for Scotland (2008/09-2011/12). 2014. http://www.foodstandards. 


\section{Original article}

gov.scot/national-diet-and-nutrition-survey-rolling-programme-results-years-1-4combined-scotland-200809 (accessed Jul 2016).

31 Harding SK, Page AS, Falconer C, et al. Longitudinal changes in sedentary time and physical activity during adolescence. Int I Behav Nutr Phys Act 2015;12:44.

32 Mitchell JA, Pate RR, Dowda M, et al. A prospective study of sedentary behavior in a large cohort of youth. Med Sci Sports Exerc 2012;44:1081-7.

33 Collings PJ, Wijndaele K, Corder K, et al. Magnitude and determinants of change in objectively-measured physical activity, sedentary time and sleep duration from ages 15 to 17.5y in UK adolescents: the ROOTS study. Int I Behav Nutr Phys Act 2015;12:61.
34 Hughes AR, Sherriff A, Lawlor DA, et al. Incidence of obesity during childhood and adolescence in a large contemporary cohort. Prev Med 2011;52:300-4.

35 Hughes AR, Sherriff A, Lawlor DA, et al. Timing of excess weight gain in the Avon Longitudinal Study of Parents and Children (ALSPAC). Pediatrics 2011;127:e73 0-e736.

36 Tanaka C, Reilly JJ, Huang WY. Longitudinal changes in objectively measured sedentary behaviour and their relationship with adiposity in children and adolescents: systematic review and evidence appraisal. Obes Rev 2014;15:791-803. 